\section{In vitro Sugar and Water Use in Diploid and Tetraploid Genotypes of Daylily (Hemerocallis spp.) in Liquid Medium as Affected by Density and Plant Growth Regulators}

\author{
Jeffrey Adelberg ${ }^{1}$ \\ Department of Horticulture, 247 Poole Agricultural Center, Clemson \\ University, Clemson, SC 29634 \\ Maria Delgado and Jeffrey Tomkins \\ Department of Genetics and Biochemistry, Clemson University, Clemson, \\ SC 29634
}

Additional index words. ancymidol, benzyladenine, bioreactor, heterotrophic, micropropagation, sucrose

\begin{abstract}
Two tetraploid and two diploid genotypes of Hemerocallis spp. were micropropagated on an orbital shaker in Murashige and Skoog liquid medium in a factorial combination of two sucrose concentrations $(90 \mathrm{~mm}$ and $180 \mathrm{~mm})$, two 6-benzylaminopurine (benzyladenine) concentrations $(0.32 \mu \mathrm{M}$ and $3.2 \mu \mathrm{M})$, at two densities (57 explants/L and 171 explants/L), in the presence $(0.32 \mu \mathrm{M})$ and absence of $\alpha$-cyclopyl$\alpha$-[4-mehtoxyphenyl]-5-pyrimididinmethanol (ancymidol). There were linear relationships between fresh weight and water use $\left(R^{2}=0.800, P<0.0001\right)$, dry weight and sucrose use $\left(R^{2}=0.636, P<0.0001\right)$, and relative dry weight (dry weight/fresh weight $=$ relative dry weight) to concentration of sucrose residual in medium after culture $\left(R^{2}=0.553, P<\right.$ 0.0001). Eighty-five percent of the water used and $74 \%$ of the sucrose used were incorporated as plant fresh weight and dry weight, respectively. A $1 \%$ increase in percent sucrose residual (mass/volume in spent medium) was correlated to an increase of $1.8 \%$ relative dry weight over the range $7 \%$ to $22 \%$ relative dry weight. In vessels with $90 \mathrm{~mm}$ initial sucrose, where the most growth had occurred ( $>15 \mathrm{~g}$ fresh weight), sucrose was depleted $(<0.2 \%$ sucrose $)$ and plantlets had the lowest relative dry weight $(\approx 6.9 \%)$. In vessels from $180 \mathrm{~mm}$ initial sucrose, with similarly high fresh weight, plantlets had $12.0 \%$ relative dry weight with $2.1 \%$ sucrose residual in medium. Fresh weight, dry weight, or relative dry weight of plantlets in the laboratory did not correlate with subsequent survival or growth in the greenhouse. Plantlets grown without ancymidol at the lower benzyladenine concentration acclimatized to the greenhouse with $93 \%$ survival. However, greenhouse survival of plants grown with ancymidol and a higher level of benzyladenine was only $4 \%$. 'Barbara Mitchell' was the largest plant in the laboratory, but often had poorest growth in the greenhouse. When optimizing a liquid micropropagation protocol for larger vessels, sucrose and water requirements may be directly related to targeted biomass yield, but each genotype needs to be handled independently with ex vitro validation of plant vigor.
\end{abstract}

Virtually the entire U.S. micropropagation industry relies on agar-based medium ( $R$. Strode, Agri-Starts I; Mount Dora, Fla.); yet, many micropropagated plants grow better in liquid medium than on agar (Adelberg, 2004; Berthouly and Etienne, 2005; Takayama and Akita, 2005). Liquid systems offer advantages of reduced media costs, lower labor costs, and greater efficiencies for scale-up

\footnotetext{
Received for publication 14 June 2006. Accepted for publication 18 Oct. 2006.

Supported in part by Cooperative States Research, Extension and Education Service (CSREES) project number SC-1700304.

Technical contribution no. 5258 of the Clemson University Expt. Sta.

${ }^{1}$ To whom reprint requests should be addressed. e-mail jadlbrg@clemson.edu.
}

(Etienne and Berthouly, 2002; Gross and Levin, 1999; Paek et al., 2005). Several inexpensive plastic bioreactors have been introduced for micropropagation that lessen barriers to adapt liquid-based systems. Bioreactor vessels designed for micropropagation include The Israeli LifeGuard (Ziv 1999), the French RITA (Etienne and Berthouly, 2002), BIT twin-flask in Cuba (Escalona et al., 1999), and the American Liquid Laboratory Rocker (Adelberg and Simpson, 2004). Shaker cultures are used to transition plants from agar-based culture to larger bioreactor systems, but shakers have high costs for numbers of plants produced (Takayama and Akita, 2005). Geophytes, and other herbaceous perennials with storage roots, have been most readily adaptable to bioreactor environments.
The proportion of explants to media volume and vessel size must be optimized to produce the greatest numbers of high-quality shoots from plant bioreactors (Adelberg, 2005; Berthouly and Etienne, 2005; Hahn and Paek, 2005). Plants in liquid systems grew faster than plants on agar as a result of greater exchange rates of sugar and water at the plant-medium interface (Ibaraki and Kurata, 1998). In liquid shaker culture of Hosta tokudama Tratt 'Newberry Gold', initial sucrose concentrations in media were correlated to endogenous sugar concentrations, plant dry weight (DW), and subsequent growth in the greenhouse (Gollagunta et al., 2004). Sugar and water use estimates for targeted crops would be useful to guide scale-up to larger bioreactor vessels.

Plant growth regulators influenced nutritional requirements for plants in bioreactors (Paek et al., 2005) and are used in micropropagation to promote desired morphology. For example, 6-benzylaminopurine (benzyladenine; BA) is the plant growth regulator most often used during stage II of micropropagation (multiplication) to promote axillary branching and to break apical dominance. Plant growth regulators that inhibit gibberellin synthesis were useful in bioreactor culture to improve morphology and anatomy of several geophyte crops (Ziv, 1992). Ancymidol (ANC) and paclobutrazol in liquid-based micropropagation systems reduced water uptake and vacuolization while decreasing internode length and leaf size (Ziv, 2005). Ancymidol and paclobutrazol in liquid also reduced plant size and increased the number of divisions in small, shaken flasks of Musa acuminata Colla 'Grand Naine' (Albany et al., 2005). Ancymidol reduced plant size and increased occurrence of divisions of Hosta 'Blue Vision' over a prolonged period of the culture cycle while in small, shaken jars (Maki et al., 2005). Because there is less leaf and root tissue to be cut away and discarded, smaller plants are handled more quickly during aseptic transfer processes, lowering the costly input of hood labor (Adelberg and Toler, 2004; Adelberg et al., 2005; Albany et al., 2005).

Daylilies (Hemerocallis spp.) are one of the most popular perennial landscape plants in the United States and are among the most valuable commercially micropropagated plants. Hemerocallis spp. is typically grown on agar-gelled Murashige and Skoog (MS) medium with $30 \mathrm{~g} \cdot \mathrm{L}^{-1}$ sucrose and BA. More than 40,000 hybrid cultivars derived from an original genetic base of $\approx 16$ interfertile species make up the daylily germplasm pool (Tomkins et al., 2001). Furthermore, hybridizers have used colchicine to convert many diploid cultivars, and then used the altered material as tetraploid breeding stock. As a result, the modern germplasm pool is a mix of both diploid and tetraploid cultivars.

Four daylily cultivars (two diploid and two tetraploid) with dissimilar phenotypes and pedigrees were selected for this study based on their diverse growth characteristics 
and genetic divergence as evaluated within the daylily germplasm pool using molecular genetic markers amplified fragment length polymorphism (AFLPs) (Tomkins et al., 2001). While propagating in vitro stock cultures of daylily in liquid media in small shaker vessels, the main and interactive effects of four genotypes (two diploid and two tetraploid) at two plant densities, with two sucrose concentrations, and at two concentrations of the plant growth regulators-BA and the gibberellin-antagonist $\alpha$-cyclopyl- $\alpha$-[4mehtoxyphenyl]-5-pyrimididinmethanol (ancymidol; ANC)-were observed on growth and nutrient use in vitro and subsequent performance of the plantlets in the greenhouse. The exploratory factorial was designed to establish the relative importance of several factors, and their interactions, before future work in larger vessels. We present the most significant treatment effects and establish correlative effects, valid over a wide range of conditions as a guide to a rationally approach scale-up for larger vessels.

\section{Materials and Methods}

Four cultivars (genotypes) of daylily [two tetraploid ('Mary's Gold' and 'Heart of a Missionary') and two diploid ('Barbara Mitchell' and 'Brocaded Gown')] were selected based on dissimilar pedigrees and phenotypes. Sterile explants were obtained by dissecting unexpanded buds in crown tissue in solution of $100 \%$ commercial bleach solution $(5.25 \% \mathrm{NaOCl})$ for $2 \mathrm{~min}$. Buds were plated on MS medium containing $1 \mu \mathrm{M}$ BA and 3\% sucrose, and surface sterilization was repeated if infestation persisted. Buds were propagated in 180-mL baby food jars with $35 \mathrm{~mL}$ liquid medium, and were placed on an orbital shaker at $90-\mathrm{rpm}$, under $35 \mu \mathrm{mol} \cdot \mathrm{m}^{-2} \cdot \mathrm{s}^{-1}$ photosynthetically active radiation supplied by cool white fluorescent tubes in $16 \mathrm{~h} \cdot \mathrm{d}^{-1}$, at $23 \pm 2{ }^{\circ} \mathrm{C}$. Subcultures were repeated about every 6 weeks for a minimum of 6 months.

When adequate quantities of tissue were available, the four genotypes were micropropagated in modified MS liquid medium containing high or low sucrose concentrations (90 $\mathrm{mm}$ and $180 \mathrm{~mm}$ sucrose), high or low BA concentrations $(0.32 \mu \mathrm{M}$ and $3.2 \mu \mathrm{M})$, at high or low plant densities (57 explants/L and 171 explants $/ \mathrm{L})$, in the presence $(0.32 \mu \mathrm{M})$ or absence of ANC. A control group of six jars of medium without plants accompanied the experimental vessels on the shaker to determine the water loss and to act as a control for nutrient concentrations after autoclave.

After $35 \mathrm{~d}$ in culture, plants were removed and counted. The volume of remaining medium was determined for each jar. One milliliter of medium was than removed for nutrient analysis, and the sucrose concentration was determined using a refractometer (Atago N10, Atago Instruments Ltd., Tokyo). Plants were blotted dry on paper towels and fresh weight (FW) was recorded. About $5 \mathrm{~g}$ tissue/vessel was placed in paper envelopes and dried in a convection oven at $60{ }^{\circ} \mathrm{C}$ for $48 \mathrm{~h}$, at which time DW was recorded. Dry weight was estimated as the product of FW and relative dry weight (RDW). Sucrose use was expressed as percent sucrose in initial formulation less percent sucrose in spent medium.

The remaining plants were moved to the greenhouse mist bed and planted in Fafard 3B potting media (Fafard, Anderson, S.C.). After 2 weeks under mist, plants were moved to a standard greenhouse bench and irrigated by hand as necessary for another 4 weeks. After a total of 6 weeks ex vitro, survival and whole plant FW was determined.

The experiment was a completely randomized design with four genotypes, two BA concentrations, two ANC concentrations, two sucrose concentrations, and two explant densities $(4 \times 2 \times 2 \times 2 \times 2)$ replicated three times (three vessels of each) in a factorial arrangement. Data were analyzed in JMP as analysis of variance (version 3.2.6; SAS Institute, Cary, N.C.). Hypothesis testing was conducted at $P=0.001$.

Table 1. The main effects of genotype on plant growth and media use after $35 \mathrm{~d}$ of in vitro growth and $42 \mathrm{~d}$ of subsequent growth in a greenhouse.

\begin{tabular}{|c|c|c|c|c|c|c|c|}
\hline Genotype & Ploidy & $\begin{array}{l}\text { Fresh wt. } \\
\text { (g/vessel) }\end{array}$ & $\begin{array}{c}\text { Dry wt. } \\
\text { (g/vessel) }\end{array}$ & $\%$ Dry wt & $\begin{array}{l}\text { Sucrose use } \\
(\% \text { original })\end{array}$ & $\begin{array}{c}\text { Laboratory } \\
\text { plant size } \\
\text { (no. observed) }\end{array}$ & $\begin{array}{c}\text { Greenhouse } \\
\text { plant size } \\
\text { (no. observed) }\end{array}$ \\
\hline \multicolumn{8}{|l|}{ Barbara } \\
\hline Mitchell & $2 n$ & $9.1 \mathrm{a}$ & $1.07 \mathrm{a}$ & $12.6 \mathrm{a}$ & $83 \mathrm{a}$ & $2.1 \mathrm{a}(261)$ & $2.7 \mathrm{~b}(85)$ \\
\hline Mary's Gold & $4 n$ & $8.2 \mathrm{a}$ & $0.99 \mathrm{a}$ & $12.8 \mathrm{ab}$ & $67 \mathrm{ab}$ & $1.6 \mathrm{~b}(305)$ & $4.6 \mathrm{ab}(110)$ \\
\hline \multicolumn{8}{|l|}{ Heart of a } \\
\hline Missionary & $4 n$ & $6.4 \mathrm{~b}$ & $0.82 \mathrm{~b}$ & $14.5 \mathrm{ab}$ & $65 \mathrm{ab}$ & $1.3 \mathrm{~b}(268)$ & 6.4 a (59) \\
\hline Brocaded Gown & $2 \mathrm{n}$ & $4.8 \mathrm{~b}$ & $0.64 \mathrm{c}$ & $14.7 \mathrm{~b}$ & $56 \mathrm{~b}$ & $1.1 \mathrm{~b}(242)$ & $3.8 \mathrm{~b}(63)$ \\
\hline
\end{tabular}

zPlant size was reported in grams per plant.

a, b, c represent difference of treatment means within columns that were significant by Tukey's HSD at $P=0.05$.
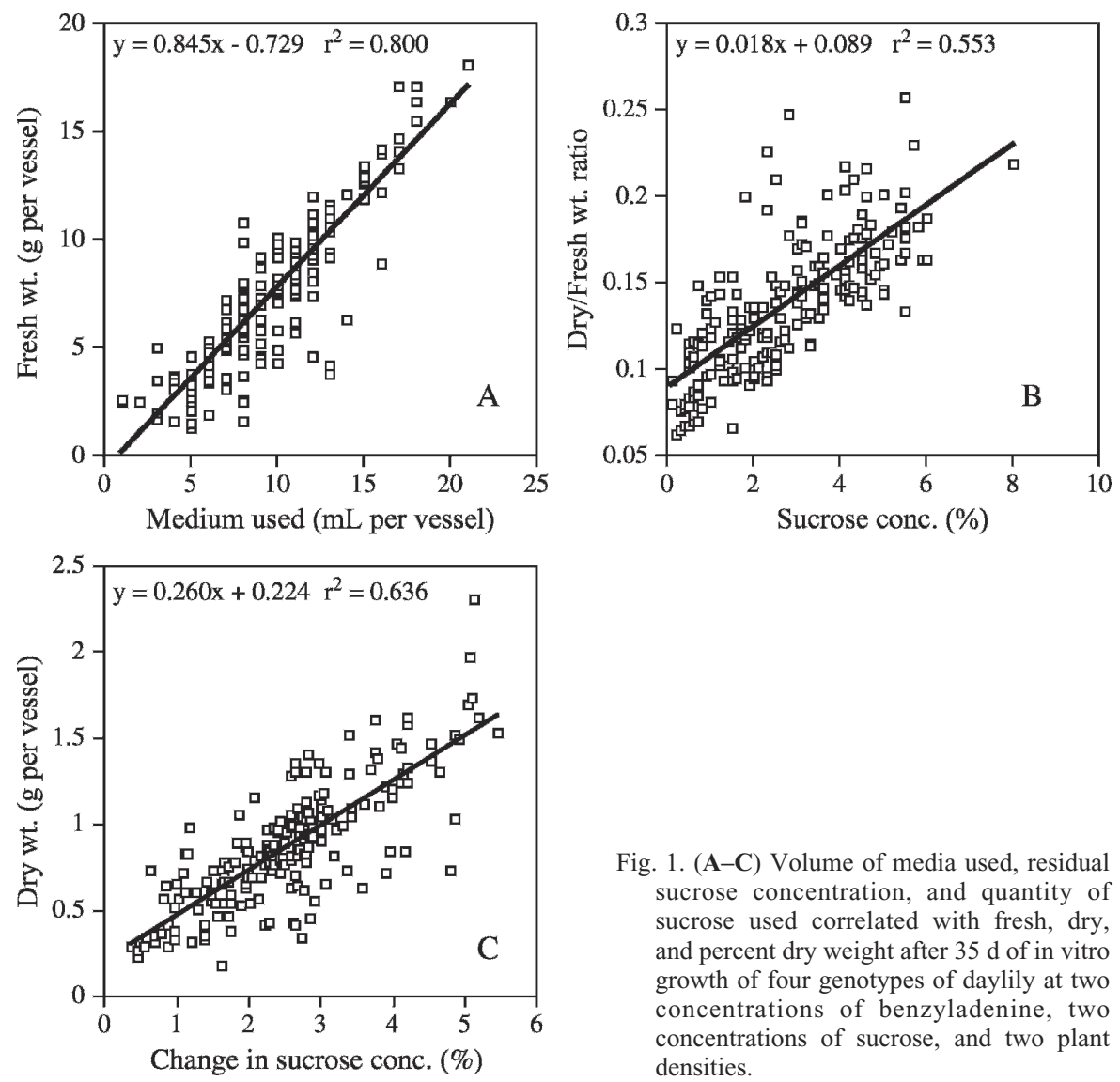

Fig. 1. (A-C) Volume of media used, residual sucrose concentration, and quantity of sucrose used correlated with fresh, dry, and percent dry weight after $35 \mathrm{~d}$ of in vitro growth of four genotypes of daylily at two concentrations of benzyladenine, two concentrations of sucrose, and two plant densities. 
density of 1.00 to $1.01 \mathrm{~g} \cdot \mathrm{mL}^{-1}$ (dependent on sucrose concentration). Therefore, water use by plant (FW - DW) can be equated with media use on a volume basis $(1 \mathrm{~mL}$ medium $=$ $1 \mathrm{~g} \mathrm{FW}-\mathrm{DW})$. After adjusting for the $2 \mathrm{~mL}$ of evaporated water/vessel during the culture period, $80 \%$ to $85 \%$ of the media volume used was incorporated as tissue FW. The $10 \%$ to $15 \%$ of media use that did not result in FW may have transpired as water, condensed on the vessel, or was otherwise uncounted. In the $5 \%$ of the vessels with greatest growth $(>15 \mathrm{~g}$ FW), $47 \%$ of the media volume remained. Therefore, the volume of water supplied in media was ample to support growth of Hemerocallis spp. in the density ranges tested. The higher density of explants in media could be retained in scale-up.

There was a linear relationship between concentration of sucrose residual in remaining medium and percent RDW of plantlets at time of harvest $\left(R^{2}=0.55, P<0.0001\right.$; Fig. 1B). For Hemerocallis spp., each $1 \%$ increase in residual sucrose concentration was correlated to a $1.8 \%$ increase in RDW over the range of $7 \%$ to $22 \%$ ( $95 \%$ confidence interval). In the $5 \%$ of the vessels with the greatest growth $(>15 \mathrm{~g} \mathrm{FW})$ and conventional (90 $\mathrm{mm}$ ) sucrose concentration, less than $0.2 \%$ sucrose remained as residual, and tissue was $6.9 \%$ RDW. The vessels with greatest growth (>15 g FW) from high initial sucrose $(180 \mathrm{~mm})$ had $2.1 \%$ sucrose residual and $12.0 \% \mathrm{RDW}$. Therefore, in the vessels with the most vigorous growth, a higher sucrose formulation was required to maintain a high relative dry matter content $(6.9 \%$ vs. $12.0 \%$ RDW). Because optimization proceeds to establish greater biomass in defined medium volumes, a higher sucrose concentration would be needed to maintain adequate plant quality.

Primarily, FW gain during heterotrophic plant culture is the result of the uptake of water, and the DW gain is mainly the result of the uptake of sugar and inorganic ions. Ibaraki and Kurata's (1998) heterotrophic growth model shows that water uptake and sugar uptake depends upon the water potential difference between the plantlet and medium. When sugar becomes depleted from medium, plants continue to grow by taking on more water relative to soluble solids. High initial sugar concentrations allowed highdensity cultures to maintain high relative dry matter content while producing large amounts of biomass. Residual sugar concentration of in vitro medium was a good index of the plants water status at the time tissue was removed from the vessel.

Dry weight increased with sucrose use, and a $0.26 \mathrm{~g} / \mathrm{vessel}$ increase in DW was correlated with each $1 \%$ of sucrose used (Fig. 1C). One percent sucrose has a mass of $10 \mathrm{~g} \cdot \mathrm{L}^{-1}$ that, when assimilated, yielded $7.4 \mathrm{~g} \cdot \mathrm{L}^{-1}$ in tissue DW. Therefore, Hemerocallis spp. in liquid medium fixed $74 \%$ of the sucrose mass as dry matter, with the remainder exhausted as $\mathrm{CO}_{2}$ and water, or remaining otherwise uncounted. Plant cells have roughly $50 \%$ conversion efficiency of organic carbon feed to final cell DW in bioreactor systems (Curtis, 1999), so we may conclude that the daylily plantlets in liquid MS medium were a relatively efficient system.

In vitro ANC treatment reduced the plantlet FW and the size of the leaf blades (Fig. 2). Reduced leaf size made it easier to divide plantlets, with less discarded materials speed- ing the technician's processing time (Adelberg et al., 2005). There was no relationship between FW, DW, RDW, and the survival of plants in the greenhouse. Although plantlets of 'Barbara Mitchell' were largest in laboratory, greenhouse plants of 'Barbara Mitchell' that survived transfer were often smaller than the greenhouse-grown plants of
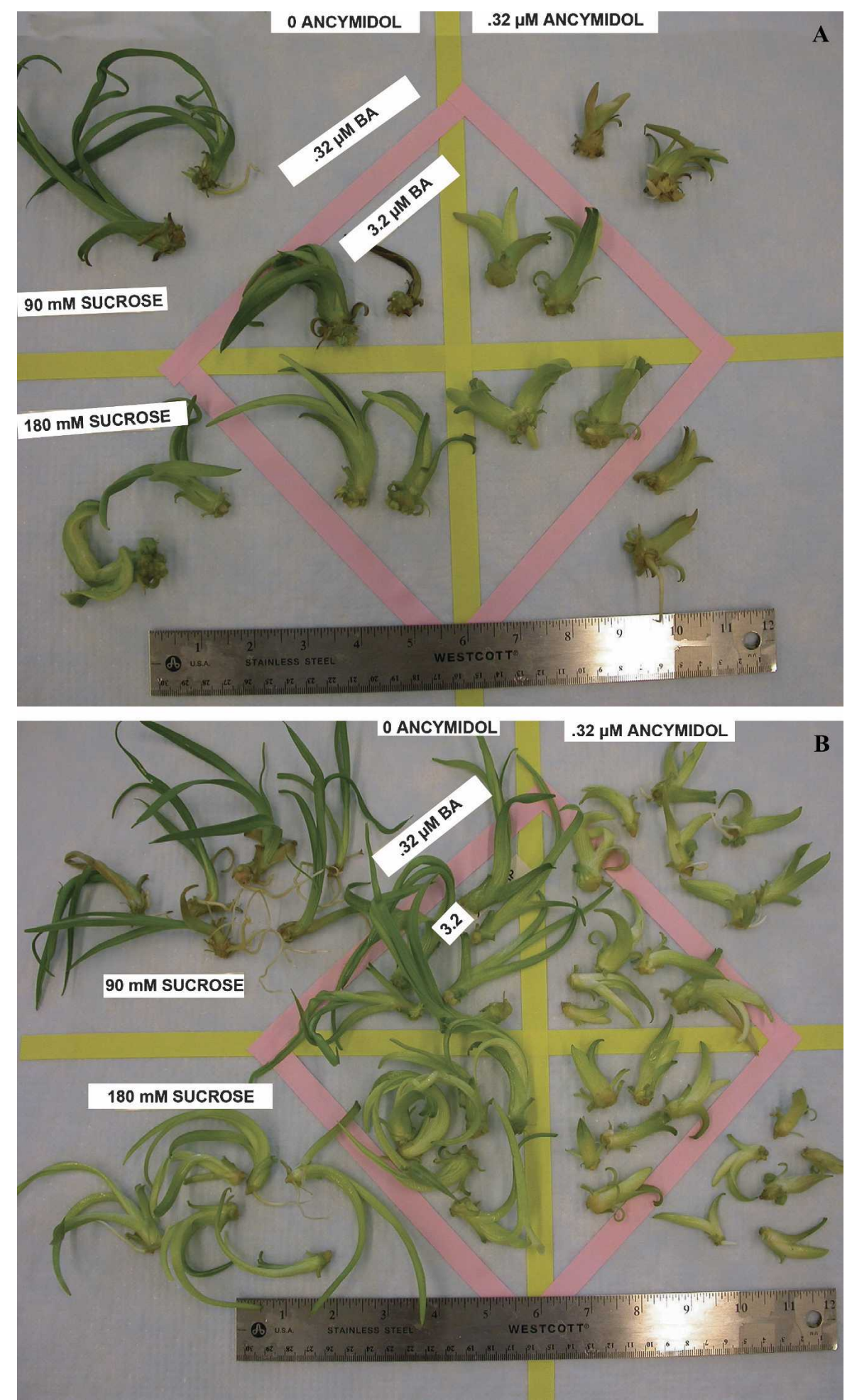

Fig. 2. Daylily cultivar Barbara Mitchell at (A) 57 explants/L (two explants/vessel) and (B) 171 explants/L (six explants/vessel) are shown after $35 \mathrm{~d}$ of culture on orbital shaker. Ancymidol treatments are to the right of the vertical bisector, high sucrose treatments are below the horizontal bisector, and high benzyladenine treatments are in the center of the diamond. 
Table 2. Ancymidol and benzyladenine (BA) concentration during $35 \mathrm{~d}$ of in vitro growth affects the survival rate (percent) of plantlets in the greenhouse $42 \mathrm{~d}$ later.

\begin{tabular}{lcc}
\hline & $\begin{array}{c}\text { No } \\
\text { ancymidol }\end{array}$ & $\begin{array}{c}\text { Ancymidol } \\
(0.32 \mu \mathrm{M})\end{array}$ \\
\hline $0.32 \mu \mathrm{M} \mathrm{BA}$ & $93 \mathrm{a}$ & $52 \mathrm{~b}$ \\
$3.2 \mu \mathrm{M}$ BA & $60 \mathrm{~b}$ & $4 \mathrm{c}$ \\
\hline
\end{tabular}

$\mathrm{a}, \mathrm{b}, \mathrm{c}$ represent difference of treatment means that were significant by Tukey's HSD at $P=0.05$.

the other three genotypes (Table 1). Plants of 'Mary's Gold', 'Brocaded Gown', and 'Heart of a Missionary' had more than tripled in mass in the greenhouse, whereas 'Barbara Mitchell' had increased only about 1.3 times in 6 weeks.

Ancymidol and BA had negative effects on greenhouse survival. Plants grown without ANC and a low concentration of BA had a good rate of survival (93\%; Table 2). High BA concentrations, with ANC produced plantlets that were poorly suited for survival (4\%). Treatment with ANC at low BA concentrations, or high $\mathrm{BA}$ concentrations in the absence of ANC produced intermediate levels of survival in the greenhouse $(52 \%$ and $60 \%$ respectively). Ancymidol and higher BA concentrations also reduced the FW of greenhouse plants, the number of storage roots, and the length of the leaf blades (data not presented). In general, the adverse carryover effects of BA on rooting of plantlets and their survival ability in the greenhouse should be carefully evaluated when selecting cytokinin (Kane, 2005). Ancymidol carryover also needs to be carefully assessed during micropropagation protocol development.

Multifactor experiments are useful at the exploratory stage of an investigation for examination of large numbers of factors and their interactions, with a reasonably sized trial. The limited amount of tissue available during scale-up to a bioreactor process is a circumstance during which small trials must address a large numbers of factors. Information gained during shaker culture bulk-up can rationally guide bioreactor-scaled process development. In this trial it was shown with Hemerocallis spp. that $1 \mathrm{~mL}$ medium is required for each $0.85 \mathrm{~g} \mathrm{FW}$ of tissue harvest anticipated (bracketed with an appropriate confidence interval). Similarly, $1 \mathrm{~g}$ sucrose is required for each 0.74 $\mathrm{g}$ DW of tissue harvest anticipated. There were no direct relationships between $\mathrm{FW}$, DW, or sucrose use, and subsequent greenhouse survival or growth. Certain factors like genotypic variation need to be empirically determined. 'Barbara Mitchell' had the largest plantlets in the laboratory but grew poorly in the greenhouse. A scaled-up micropropagation bioreactor process should include greenhouse trials of each genotype, because varieties with superior laboratory performance may become problematic in the nursery.

\section{Literature Cited}

Adelberg, J. 2004. Plant growth and sugar utilization in an agitated, thin film liquid system for micropropagation. In Vitro Cell. Dev. Biol. Plant 40:245-250.

Adelberg, J. 2005. Efficiency in thin-film liquid system for micropropagation of Hosta. Plant Cell Tissue Org. Cult. 81:359-368.

Adelberg, J. and E. Simpson. 2004. Intermittent immersion vessel apparatus and process for plant propagation. US patent no. $6,753,178 \mathrm{~B} 2$.

Adelberg, J. and J. Toler. 2004. Comparison of agar and an agitated, thin-film liquid system for micropropagation of ornamental elephant ears. HortScience 39:1088-1092.

Adelberg, J., M. Delgado, and J. Tomkins. 2005. Ancymidol and liquid media improved micropropagation of Hemerocallis cv. Todd Monroe on the Rocker Thin Film Bioreactor. J. Hort. Biotech. 80:774-778.

Albany, N., E. Gonzalez, J. Vilchez, L. Garcia, D. Feria, N. Perez, Z. Sarria, B. Perez, and J. Clavelo. 2005. Use of growth retardants for banana (Musa AAA cv. Grand Naine) shoot multiplication in temporary immersion systems, p. 213-224. In: A. Hvolsef-eide and W. Preil (eds.). Liquid culture systems for in vitro plant propagation. Springer, Dordrecht, the Netherlands.

Berthouly, M. and H. Etienne. 2005. Temporary immersion system: A new concept, p. 165-196. In: A. Hvolsef-eide and W. Preil (eds.). Liquid culture systems for in vitro plant propagation. Springer, Dordrecht, the Netherlands.

Curtis, W. 1999. Achieving economic feasibility for moderate value food and flavour additives: A perspective on cost productivity and proposal for production technology cost reduction, $\mathrm{p}$. 225-236. In: T.J. Fu, G. Sing, and W. Curtis (eds.). Plant cell and tissue for production of food ingredients. Kluwer Academic/Plenum Publishers, New York.

Escalona, M., J. Lorenzo, B. Gonzalez, M. Daquinta, J. Gonzalez, Y. Desjardins, and C. Borroto. 1999. Pineapple (Ananas comosus L. Merr) micropropagation in temporary immersion systems. Plant Cell Rep. 18:743-748.

Etienne, E. and M. Berthouly. 2002. Temporary immersion systems in plant micropropagation. Plant Cell Tissue Org. Cult. 69:215-231.

Gollagunta, V., J. Adelberg, N. Rajapakse, and J. Rieck. 2004. Media composition affects carbo- hydrate status and quality of Hosta tokudama Tratt. 'Newberry Gold' micropropagules during low temperature storage. Plant Cell Tissue Org. Cult. 77:125-131.

Gross, A. and R. Levin. 1999. Design consideration for mechanized micropropagation laboratory, p. 637-642. In: A. Altman, M. Ziv, and S. Izhar (eds.). Plant biotechnology and in vitro biology in the 21 st century. Kluwer Academic Publishers, Dordrecht, the Netherlands.

Hahn, E. and K. Paek. 2005. Multiplication of Chrysanthemum shoots in bioreactors as affected by culture method an inoculation density of single node stems, p. 143-154. In: A. Hvolsef-eide and W. Preil (eds.). Liquid culture systems for in vitro plant propagation. Springer, Dordrecht, the Netherlands.

Ibaraki, Y. and K. Kurata. 1998. Relationship between water content of Cymbidium protocorm-like body and growth. In: L.F.M. Marcelis (ed.). Crop models in protected cultivation. Acta Hort. 456:61-66.

Kane, M. 2005. Shoot culture procedures, p. 145157. In: R. Trigiano and D. Gray (eds.). Plant development and biotechnology. CRC Press, Boca Raton, Fla.

Maki, S., M. Delgado, and J. Adelberg. 2005. Time course study of ancymidol on micropropagated Hosta. HortScience 40:764-766.

Paek, K., D. Chakrabaty, and E. Hahn. 2005. Application of bioreactor systems for large scale production of horticultural and medicinal plants, p. 95-116. In: A. Hvolsef-eide and W. Preil (eds.). Liquid culture systems for in vitro plant propagation. Springer, Dordrecht, the Netherlands.

Takayama, S. and M. Akita. 2005. Practical aspects of bioreactor application in mass propagation of plants, p. 61-78. In: A. Hvolsef-eide and W. Preil (eds.). Liquid culture systems for in vitro plant propagation. Springer, Dordrecht, the Netherlands.

Tomkins, J., T. Wood, A. Westman, L. Barnes, and R. Wing. 2001. Evaluation of genetic variation in the daylily (Hemerocallis spp.) using AFLP markers. Theor. Appl. Genet. 102: 489-496.

Ziv, M. 1992. The use of growth retardants for the regulation and acclimatization of in vitro plants, p. 809-817. In: C. Karsen, L. Van Loon, and D. Vregdenhil (eds.). Progress in plant growth and regulation. Kluwer Academic Publishers, Dordrecht, the Netherlands.

Ziv, M. 1999. Organogenic plant regeneration in bioreactors, p. 673-676. In: A. Altman et al. (eds.). Plant biotechnology and in vitro biology in the 21 st century. Kluwer Academic Publishers, Dordrecht, the Netherlands.

Ziv, M. 2005. Simple bioreactors for mass propagation of plants, p. 213-224. In: A. Hvolsefeide and W. Preil (eds.). Liquid culture systems for in vitro plant propagation. Springer, Dordrecht, the Netherlands. 